San Jose State University

SJSU ScholarWorks

Faculty Publications

Social Work

January 2003

\title{
Progress and opportunities in lesbian, gay, bisexual and transgender health communications
}

Laurie A. Drabble

San Jose State University, laurie.drabble@sjsu.edu

J. Keatley

University of California - San Francisco

G. Marcelle

Social and Health Services Ltd

Follow this and additional works at: https://scholarworks.sjsu.edu/social_work_pub

Part of the Lesbian, Gay, Bisexual, and Transgender Studies Commons, Other Public Health Commons, Psychology Commons, and the Social Work Commons

\section{Recommended Citation}

Laurie A. Drabble, J. Keatley, and G. Marcelle. "Progress and opportunities in lesbian, gay, bisexual and transgender health communications" Journal of Clinical Research and Regulatory Affairs (2003): 205-227. https://doi.org/10.1081/CRP-120021081

This Article is brought to you for free and open access by the Social Work at SJSU ScholarWorks. It has been accepted for inclusion in Faculty Publications by an authorized administrator of SJSU ScholarWorks. For more information, please contact scholarworks@sjsu.edu. 
This is an Author's Original Manuscript of an article whose final and definitive form, the Version of Record, has been published in the Journal of Clinical Research and Regulatory Affairs 20 (2), 205-227. Available online at: http://informahealthcare.com/doi/abs/10.1081/CRP-120021081

The appropriate citation for this manuscript is:

Drabble, L., Keatley, J., \& Marcelle, G. (2003). Progress and opportunities in lesbian, gay, bisexual and transgender health communications. Journal of Clinical Research and Regulatory Affairs 20 (2), 205-227.

Title:

Progress and Opportunities in Lesbian, Gay, Bisexual and Transgender Health Communications

Authors and Affiliations $\quad$ Laurie Drabble, Ph, D., MSW, MPH

Assistant Professor, College of Social Work,

San Jose State University

Joanne Keatley, MSW

Project Director, Health Studies for People of Color, CAPS/University of California, San Francisco

George Marcelle, Communications Director

Social and Health Services, Ltd.

Los Angeles, CA

Acknowledgements:

The authors acknowledge the Gay and Lesbian Medical Association (GLMA) for publishing the LGBT Healthy People 2010 ("Healthy People 2010: Companion Document for Lesbian, Gay, Bisexual, and Transgender (LGBT) Health”) and gratefully thank Craig Packer, lead writer of the Companion Document chapter on Health Communications, for his contributions to the conceptualization and content of this article.

\section{ABSTRACT}

This article describes elements of effective health communication and highlights strategies that may best be adopted or adapted in relation to lesbian, gay, bisexual and transgender (LGBT) populations. Studies have documented the utility of multidimensional approaches to health communication from the macro level of interventions targeting entire populations to the micro level of communication between health care provider and consumer. Although evidence of health disparities in LGBT communities underscores the importance of population-specific interventions, health promotion campaigns rarely target these populations and health communication activities seldom account for the diversity of LGBT communities. Advances in health communication suggest promising direction for LGBT-specific risk prevention and health 
promotion strategies on community, group, and provider/consumer levels. Opportunities for future health communication efforts include involving LGBT communities in the development of appropriate health communication campaigns and materials, enhancing media literacy among LGBT individuals, supporting LGBT-focused research and evaluation of health communication activities, and ensuring that health care providers possess the knowledge, skills, and competency to communicate effectively with LGBT consumers. 


\section{PROGRESS AND OPPORTUNTIES IN LESBIAN, GAY, BISEXUAL AND TRANSGENDER HEALTH COMMUNICATIONS}

\section{OVERVIEW}

Health communication is an essential element of disease prevention and health promotion efforts. ${ }^{1-4}$ Health communication "is any type of communication whose content in concerned with health"4 and may take many forms from direct doctor-patient communication to mass media health promotion campaigns. Research suggests that health communication campaigns have been successful in relation to a wide array of health issues including HIV/AIDS prevention, prevention of alcohol and other drug problems, smoking cessation and prevention of tobacco use, reduction in cardiovascular mortality, increasing seatbelt use, and improving reproductive health practices. $^{1,4,5}$

Health communication can be designed to promote individual behavior change, define or redefine health problems, and advance policy changes. Effective health communication can impact individuals by increasing awareness of specific health risks and solutions, illustrating skills designed to protect or improve health, helping consumers make health-related choices, and reinforcing adoption of recommended behaviors. ${ }^{3,6}$ Consumer demand for appropriate health services and access to available resources can be enhanced with the help of health communications. ${ }^{3}$ Health communication can also facilitate public discussion of health issues, shape public policy and promote social norms to reduce health problems and promote health. ${ }^{1,5,7}$ Changes in policy and social norms have a significant influence on the health of communities. For example, regulatory measures such as alcohol tax increases, increasing the minimum drinking age to 21, reducing the number of outlets selling alcoholic beverages, mandating responsible beverage service, and restricting sales at public events are policy-related strategies that have often been effective in reducing alcohol-related problems among youth. ${ }^{8,9}$

In spite of advances made in the health communications field, application of promising practices and research on strategies targeting lesbian, gay, bisexual and transgender (LGBT) communities remains modest or absent. Approaches to health communication specifically related to HIV/AIDS prevention have been developed in gay male communities ${ }^{10-13}$ and with other hard to reach populations including men who have sex with men who do not identify as gay, women who engage in sex for drugs, injection drug users, female sex partners of injection drug users, and high-risk youth. ${ }^{14-16}$ These approaches, however, have yet to be broadly applied to the multiple health issues facing LGBT individuals such as breast cancer, domestic and other interpersonal violence, sexually transmitted diseases (STDs), substance abuse, mental health, and health problems associated with aging.

The continued growth of the health communication field, evolving health advocacy organizing in lesbian, gay, bisexual and transgender community, and government efforts to address health disparities create a rich environment for developing, delivering and evaluating population specific health communications. The federal government, specifically the Department of Health and Human Services (HHS) has defined health goals for the nation with a special focus on reducing health disparities as part of Healthy People 2010. Sexual orientation is included in 29 
specific objectives in Healthy People 2010 across 10 focus areas (e.g., access to care, HIV, substance abuse, and tobacco use; however, most of these have no corresponding data collection tracking system specific to sexual orientation). ${ }^{17}$ Specific objectives for lesbian, gay, bisexual and transgender populations are not included in the health communication focus area of Healthy People 2010. ${ }^{17}$ Nonetheless, several objectives in the Health Communication area are salient to lesbian, gay, bisexual and transgender communities including goals to increase research and evaluation based health communications activities, enhance health literacy in marginalized groups, expand access to quality health information and support through technology, and improve communications between health consumers and providers. This article examines opportunities for advancing health communications in lesbian, gay, bisexual and transgender communities based on these broad goal areas.

\section{HEALTH COMMUNICATION CAMPAIGNS AND LGBT COMMUNITIES}

Research suggests that there are disparities in health risks and protective factors between LGBT communities and the population as a whole. Lesbians, gay men and bisexuals appear to be more likely to use tobacco and to report alcohol or other drug problems. ${ }^{18-20}$ Contrary to popular assumption, many adults, and particularly adolescents, who identify as lesbian and gay, have high risk sex with opposite sex partners. ${ }^{21,22}$ Lesbians may engage in behaviors that increase their risk for health problems in comparison to heterosexual women and may be more likely to avoid health screening and to delay care. ${ }^{23-25}$ Gay, lesbian and bisexual adolescents appear to be at higher risk for substance abuse, suicide, depression, school dropout, and higher risk sexual behavior than their heterosexual counterparts. ${ }^{26-30}$ Gay and lesbian youth are frequently rejected from their homes or runaway because of homophobia ${ }^{31}$ and rates of tobacco, alcohol and other drug use among runaway homeless youth are substantially higher than youth in the general population. ${ }^{32}$ Assessment of needs among transgender communities reveal substantial concern about specific health issues including HIV-related risks and alcoholism and drug use ${ }^{33-37}$. Other issues significant to transgender health include needs related to housing, employment and health care $^{36}$ as well as risks associated with shame and isolation, sexual identity conflict, and sharing needles when injecting hormones. ${ }^{33}$

\section{Multi-Level Health Communications: Strategies that Work}

Population-based health campaigns have traditionally used mass communication such as print, radio, and television to deliver health messages. Not all mass communication strategies for improving health are effective. For example, mass communication campaigns delivered through public service announcements and intended to prevent HIV/AIDS failed to reach those at greatest risk of HIV/AIDS including men who have sex with men, lacked specificity in suggested behavior changes (e.g., use of condoms) largely because of conservative political pressure, and neglected to use current theory related to facilitating behavioral change. ${ }^{38}$

Research suggests that health communication campaigns successfully facilitate health-related behavior change, particularly when these strategies use a multifaceted approach that include a focus on changing attitudes and behaviors among individuals, facilitating change in social norms, and shifting institutional behavior including policy changes. ${ }^{39}$ A variety of approaches may be used in health communications including persuasion aimed at attitude change, diffusion of 
innovations through adoption and dissemination of ideas via opinion leaders, social marketing (generally engineered according to product, price, place and promotion), media literacy, and media advocacy. ${ }^{40}$ Individually focused appeals that neglect the social and political context of health behaviors are often less effective ${ }^{41}$ and may promote "blaming the victim." ${ }^{\text {42 }}$ In addition, approaches that emphasize individual beliefs often view culture as a "barrier" rather than positively as a context to be considered in planning communication strategies. ${ }^{43}$ By contrast, community-centered prevention and health promotion shifts attention from the individual to group-level change and emphasizes the empowerment of individuals and communities to effect change on multiple levels. Health communication campaigns require multiple strategies aimed at influencing both environmental factors and patterns of behavior in different levels of a community (e.g., social networks, groups, and local media). ${ }^{44}$

Multi-faceted and multi-level communication efforts are critical in health communications designed for LGBT communities. HIV/AIDS prevention campaigns using population-specific outreach, community-based support, and media strategies have been proven effective with men who have sex with men. ${ }^{10}$ and with transgender populations. ${ }^{45,46}$ Community theory and research suggest that prevention or other health communications targeting marginalized groups must be based in the economic, social and cultural context of these communities and reflect the identities of diverse individuals in terms of gender, gender identity, sexual orientation, age, and race and ethnicity. ${ }^{12,47,48}$ For example, health communications targeting transgenders and transsexuals need to account for the broader social and cultural context that includes discrimination, high prevalence of sex work (related to unemployment and housing discrimination), alienation from family, and lack of representation in political and social institutions. ${ }^{34,37}$

Targeted Health Communication: Reaching Diverse LGBT Communities

Although LGBT communities are often marginalized and stigmatized in relation to the dominant culture, the needs and experiences of subgroups vary substantially. Advocates for LGBTcompetent health communication need to recognize the diversity in community norms, values, information needs, and literacy levels within LGBT communities. For example geographic differences between men who have sex with men suggest the need for different HIV/AIDS prevention communication. Men who have sex with men who live outside of "gay ghettos" in cities may be less likely to identify as gay, to be involved in the gay community, to be tested for HIV, and to be reached through LGBT communication channels. ${ }^{49}$ LGBT individuals who reside in rural areas, who do not self-identify as gay or bisexual, or who are members of communities of color can be expected to have health information needs that differ greatly from any assumed norm.

Health communications that are tailored to address the specific needs of different individuals appear to be more effective in supporting changes in health behaviors than generic messages. ${ }^{50,51}$ These considerations are particularly relevant for LGBT communities as health communicators must understand that LGBT communities mirror the general population in relation to diversity of age, region, socioeconomic status, and race and ethnicity. LGBT health communication materials must be culturally competent and linguistically accessible to the local community for which the materials are developed. Health communications targeting LGBT and other marginalized communities are most effective when they are non-judgmental and sensitive to the "on-the-street, 
survival-oriented, real world complexity” of clients lives. ${ }^{15}$ A diverse range of customized messages should be developed so that the health needs of LGBT people can be adequately addressed. Public-private partnerships and collaborations could be created involving LGBT organizations and consumers as coparticipants in designing, implementing, and disseminating health communication activities. As a case in point, gay, lesbian and bisexual adolescents benefiting from gay sensitive HIV instruction in school reported lower levels of sexual risk behaviors and less substance use compared to their cohorts in schools with low or no LGBTsensitive instruction. ${ }^{26}$

\section{Use of Media in Promoting Healthy LGBT Communities}

The media may be employed as a tool in multi-level health communication and prevention campaigns targeting LGBT communities. Emerging media strategies that are evidenced to be effective in supporting changes in community norms and policies include media advocacy, counter-advertising, and entertainment-education.

Media advocacy, using the media to strategically apply pressure for policy change ${ }^{52,53}$, can also be a powerful tool for both adults and youth to have a voice in shaping the social and policy environment in their communities. Using media advocacy to advance policy changes also applies to gay media markets and advocacy for broad legislative policies should also include LGBT media. In a discussion of media advocacy as a tool that many communities have used successfully to counter alcohol and tobacco promotions and advance alcohol and tobacco control policies, Jernigan and Wright ${ }^{52}$ describe one action by LGBT activists:

A loose coalition of gay and lesbian activists and organizations, parents groups, and researchers used a national conference on the relationship between HIV transmission and alcohol use to bring media attention to their contention that alcohol ads that connect drinking with sex promote high-risk behavior and the spread of AIDS. They asked the alcohol companies to "put a condom on their advertising." They also had a larger goal: to break the media's silence about the link between drinking, unsafe sex, and HIV transmission (p. 312).

Use of counter-ads are a useful tool for contextualizing health problems, focusing attention on the misinformation promoted by the alcohol (or tobacco) industry, and generating support for change in policy. ${ }^{54}$ An evaluation of anti-smoking campaigns found that counter-advertising strategies were successful and that messages focusing on industry manipulation and secondhand smoke were the most effective strategies for reducing consumption and challenging cultural norms that enable smoking. ${ }^{55}$ Efforts to counter tobacco advertising in LGBT communities are documented in a report on the first federally funded conference in prevention of tobacco and alcohol problems in LGBT communities including counter-ads in LGBT media venues and a community based campaign that successfully reduced tobacco point-of-sale advertising among stores in one LGBT neighborhood (Castro area in San Francisco). ${ }^{56}$

Efforts to infuse health education messages into popular entertainment shows is a relatively new strategy in the U.S., although it is commonly used in other countries. ${ }^{4}$ Although increasing positive health portrayals in the media is unlikely to facilitate policy change, it may hold more 
promise as a health promotion strategy than the use of public service announcements. ${ }^{57}$ Entertainment media as a major source of both effective public health communication, and as powerful purveyors of pro-use and unhealthy norms setting have received increasing attention. Government and private organizations have published research findings relating to the frequency and nature of tobacco, alcohol, and drug references in popular movies, television, and popular music $^{58-60}$, strongly suggesting that these influence youth attitudes and practices. These and other studies addressed the impact of entertainment media on substance abuse among young people in the population at large, without reference to specific groups.

Numerous articles have commented on the increasing number of LGBT characters and situations seen in both network and cable television programming, including "gay-themed" or LGBTspecific entertainment vehicles (e.g., “Ellen,” “Will \& Grace,” “Queer as Folk,”), and many popular recording artists are either openly gay or are believed to have particular LGBT audienceappeal. However no content reviews of these entertainment media appear to have been undertaken. In addition, LGBT characters have been noted in many recent theatrically-released motion pictures; a burgeoning "lesbian and gay" film industry supports a growing number of annual LGBT film festivals; and LGBT's appear to be at least as proportionately significant a market for "adult" entertainment as the non-LGBT population (adult movies and video are said to represent about 25 percent of the "Hollywood" entertainment industry, and to be among its fastest-growing segments.) It is not known what the health-related content of these entertainment products is, how it compares to the content of popular movies, music and television in general and what, if any, role this plays in LGBT substance abuse or other health behaviors.

\section{RESEARCH AND EVALUATION OF LGBT HEALTH COMMUNICATIONS}

The multiple negative health risks faced by LGBT individuals coupled with the diversity of LGBT communities require high quality, creative and evidence-based health communication and health promotion interventions. To date, research on effective health communication strategies for LGBT communities has been largely limited to the HIV prevention and treatment adherence literature. Promising practices in health communication are emerging out of research literature examining the impact of innovations including building collaborative relationships with gay and bisexual male community members, ${ }^{13}$ developing culturally specific HIV communication programs $^{12}$, obtaining endorsements of opinion leaders ${ }^{11}$, and creating other community-level prevention interventions. ${ }^{10,14}$ However, research and evaluation for other LGBT health areas is scarce.

Lessons learned from HIV/AIDS health communications could help inform research efforts related to other health issues. In addition, gaps related to HIV/AIDS communications, especially in relation to underserved populations should be addressed. For example, risk correlates and social circumstances of many transgender populations differ significantly from gay men who have frequently been targeted in HIV/AIDS prevention. ${ }^{36}$ The particular needs of female to male transgender individuals have been largely ignored in health intervention and promotion efforts. The health communication needs of men who have sex with men are not homogenous and should be further researched. For example, issues of discrimination and identity appear to impair the effect of HIV communications among African American men who have sex with men. ${ }^{12}$ African 
American and Hispanic/Latino men who have sex with men are disproportionately impacted by HIV and are in need of evidence-based HIV prevention programs. ${ }^{61}$ The challenges inherent in researching LGBT populations and the urgency for doing so is articulated by researchers dedicated to hard-to-reach populations: ${ }^{16}$

"For highly mobile, very small, or furtive populations, both intervention activities and conventional quantitative research encounter formidable technical difficulties. Despite these barriers, empirical inquiry needs to be advanced rapidly for behavioral science concepts to be effectively applied to the control of this epidemic”(p. 495).

In addition to the need for evaluation of specific interventions, a number of methodological issues related to research of LGBT populations demand attention. Measures used to define lesbian, gay, and bisexual populations vary between studies ${ }^{17}$. Results based on sexual identity may have different implications for health communication than those based on sexual behavior. In addition, it is often difficult to obtain population-based data on largely invisible and stigmatized populations and the ability to generalize with nonprobablity samples is limited. This is particularly problematic for gathering information, and determining and legitimizing the health communication needs of populations often neglected in studies such as transgender communities. Other problems include a need for strengthening connection between community based organizations and research institutions, a paucity of research on health related risk and protective factors to guide health promotion efforts, and a lack of standards between studies. For example, difficulties in comparing studies of HIV/AIDS health communication underscore the need for minimum standards for intervention components and research methodologies for HIV/AIDS campaigns. $^{47}$

Successes documented among gay and bisexual men around HIV prevention goals highlight the value of integrated health promotion approaches. Such multifaceted approaches pose significant research challenges. Nevertheless, the relative success of mainstream campaigns around tobacco control, cardiovascular health, childhood immunization and other interventions in support of child survival that generally use a combination of clinical preventive care, social marketing, media and policy advocacy to change social norms, and community-based support for recommended behaviors ${ }^{1}$ challenges LGBT health professionals to develop equivalent, comprehensive health promotion efforts that are monitored for effectiveness. Centers of Excellence focused on LGBT health that have been developed or are in formation at universities around the country and community based organizations are promising sources for such research. The need for development and evaluation of LGBT specific interventions is consistent with Healthy People 2010 objectives calling for an increase in the proportion of health communication activities that include research and evaluation and to increase the number of centers for excellence that seek to advance the research and practice of health communication. ${ }^{62}$

\section{HEALTH LITERACY AND MEDIA LITERACY IN LGBT COMMUNITIES}

Health literacy is defined by "the degree to which individuals have the capacity to obtain, process, and understand basic health information and services needed to make appropriate health decisions. ${ }^{63}$ Printed health communications are often written at a literacy level that exceeds that of the intended audience. Communications that are not inclusive of different literacy levels fail to 
reach the populations most in need of health information and services. Addressing health disparities entails closing the gap in health literacy by 1) development of appropriate written materials and 2) enhancement of skills among individuals with limited literacy. ${ }^{62}$ LGBT communities are representative of and often have access to individuals who have been marginalized and who may have low literacy skills. LGBT health, human service and social organizations have an important role to play in the Healthy People 2010 objective of improving the health literacy of persons with inadequate or marginal literacy skills. LGBT health advocates and providers also have a role to play in helping craft messages that are not only accessible but that are meaningful to LGBT consumers. For example, “mainstream” HIV/AIDS prevention communications targeting men who have sex with men that shy away from integrating explicit recommended behaviors and maintaining a sex-positive tone are unlikely to reach the intended audience - regardless of the accessibility of the writing and the format. In addition, there is a dearth of health information for specific populations such as transgender groups. Transgenderspecific HIV education/ prevention materials and transgender-related health care information ranked as the top service priorities in a transgender needs assessment survey in one urban area of the U.S. ${ }^{36}$ Findings from another large qualitative study of male-to-female (MTF) and female-tomale (FTM) transgendered individuals indicate that HIV education, media and referral information are often ineffective because they are "not factually or culturally appropriate for the transgender community" and tend to use images that do not reflect the body or self-image of FTM or MTF individuals. $^{34}$

Media literacy, or the capacity to understand, analyze and think critically about broader media messages related to health, is also an important skill for individuals and communities. Media literacy is particularly important given the pervasiveness of media in contemporary society and the degree to which media impacts leisure time and public perception about the social, political and economic environment. ${ }^{64}$ Ideally, media literacy allows individuals and communities not only to critique and think independently about the messages they receive but to analyze the issues related to power and profit that may underlie these messages. ${ }^{65}$ In this sense, media literacy helps "people become sophisticated citizens rather than sophisticated consumers.”"65

The existence of grassroots agencies and LGBT community media presents an important opportunity to reach and educate LGBT individuals with critical health promotion and disease prevention messages. Moreover, LGBT individuals and communities have an opportunity to become more "sophisticated citizens" in an environment where target marketing is common practice by commercial entities whose products may be harmful. For example, LGBT communities have been increasingly targeted with specialized marketing from alcohol and tobacco industries, even while research suggests that alcohol, tobacco and drug related problems may be higher in LGBT communities than the population as a whole. ${ }^{66}$ Inclusion in the economic marketplace is symbolic of progress toward social acceptance for many LGBT individuals and communities. ${ }^{67}$ At the same time, community organizations and leaders need to critically consider the environmental impact of sponsorship, promotions, donations and advertising by companies whose products impact LGBT health and whose motives may be driven more by profit than public health. Target marketing may undermine the health of individuals through provision of biased information ${ }^{66}$ and may indirectly influence the degree to which community organizations challenge industry messages ${ }^{68,69}$ LGBT organizations and media entities can adopt policies (e.g., prohibiting or limiting certain promotions or advertising) to affirm the value that 
they place on LGBT health and to ensure their independence from profit-making influences in the pursuit of their mission. ${ }^{66}$

\section{LGBT HEALTH COMMUNICATIONS VIA THE INTERNET/WORLD WIDE WEB}

Increasingly, health improvement communications use new technologies, such as CD-ROM, health-related Web sites, email, audiotex (pre-recorded messages accessed by telephone), and online support groups to target audiences, tailor messages, and engage individuals in interactive exchanges about health. ${ }^{70-72}$ Telemedicine uses a variety of traditional and emerging technologies and collaborative alliances "to provide and support health care when distance separates the participants."73 Interactive videos have been successfully used to facilitate shared decision making between health consumers and providers ${ }^{74}$ and interactive television has provided a vehicle for geographically isolated patient and providers to consult with specialists ${ }^{75}$. Internet and other technology can also be used to facilitate collaboration between health experts. ${ }^{76}$.

The Wall Street Journal online (WSJ.com) of May 1, 2002 reported that the latest Harris Poll of 707 adults from March 13 to 19, 2002 found "some 110 million U.S. Web users have sought health-care information online in the past year, up from 97 million in 2001.” Neither Harris nor anyone else has developed comparable data specific to LGBT people, nor can it be determined what portion of those 110 million health information consumers turning to online resources in 2002 were LGBT. No one has determined whether the needs of LGBT's in search of health information online are met more satisfactorily, less satisfactorily, or just as satisfactorily as those of non-LGBT searchers.

What can be noted with concern is that there is less LGBT-identified health information available on the World Wide Web, compared to online health information communications for the population in general, and for specific health conditions (i.e., cancer, diabetes, etc.). The notable exception is in the area of HIV/AIDS, with many websites either specifying or implying that some or all of their content is directed at those who engage in same-sex behavior.

A June 15, 2002 Google search on the word "health” produced 71,800,000 possible hits, on "gay health" 1,430,000, on "lesbian health," 1,060.000, on "LGBT health" 27,000, on "bisexual health" 242,000, on "transgender health” 106,000. Many of the sites produced in the first several pages of these searches were HIV/AIDS-related. At the same time, "gay substance abuse" produced a possible 99,200 links, and "gay addiction” 127,000 possibilities.

The first site Google offered in response to "gay addiction” offers an example of the possible potential demand for expanded online LGBT health communications. NALGAP, the National Association of Lesbian \& Gay Addiction Professionals," at www.nalgap.org is a site operated by the very small non-profit membership association, founded in 1979. The group has only intermittent, part-time staff and offers only basic resource links and less than a handful of published references at its site. In May, 2002, the site received a total of 781 visits. The total traffic to this site is miniscule compared to what many major commercial and non-commercial websites, even within the broad area of "health," are known to generate. However, nalgap.org is not advertised, has had virtually no marketing of any kind, and links to it are currently in few 
other websites, suggesting that some hundreds of LGBT's and/or those serving them, may be seeking information of the kind NALGAP could provide in any given month.

Again, there is no detailed analysis of visitors to LGBT health sites. However, some sites such as the NALGAP online pages provide an e-mail option. Thus NALGAP has received queries via its site, ranging from help requests from active LGBT drug/alcohol users, to media representatives seeking information for articles relating to LGBT health, to researchers hunting for scarce data and published references related to LGBT substance abuse. Interestingly, NALGAP's limited online experience thus far may confirm the assumptions of some LGBT health advocates that LGBT's in search of online health information have needs and questions unlikely to be answered by online health communications resources designed for the public at large.

Healthy People 2010 calls for an increase in the proportion of households with internet access from home and an increase in the proportion of Web sites that disclose information that can be used to assess the quality of the site. ${ }^{77}$ The ability to access information on health issues and specific medical conditions in the privacy of home may be particularly helpful for individuals who may feel stigmatized by the dominant culture and reluctant to disclose their sexual orientation or gender identity to health providers. As a case in point, families and patients dealing with intersexuality (congenital sexual ambiguity) often wish to communicate with others that share their experience. However, this need often remains unmet because intersexuality is relatively uncommon (about 1 in every 2,000 births) and because parents, patients, and clinicians have often been reluctant to openly discuss sexual issues. Consequently, support groups for intersexuality are flourishing on the Internet, and referrals to these important sources of information and peer support address an important need. The Internet may also be used effectively by LGBT mental health clinicians and clients for communication, support and referrals. ${ }^{78}$

Multiple sources for Internet access may be important for some LGBT populations. Given the high prevalence of problems among transgender populations with housing and economic survival, it may be unrealistic to assume ease of Internet access from home. For LGBT youth in particular, home access alone is not sufficient to overcome privacy and confidentiality concerns and to guarantee access to sensitive information. LGBT youth may not be "out" to their parents, may not have adequate privacy when accessing the Internet at home, or may have access to LGBT health information blocked, inadvertently or deliberately, by commercial filtering software that fails to distinguish between health information and erotica. Access to LGBT-related health information must also be available in public settings, such as schools and libraries. To facilitate such availability, grants to local school districts for library services might be contingent upon allowing access to such health-related information without filtering and software vendors might be given economic incentives to produce software for either home or institutional use that does not filter LGBT-related health information.

Although the Internet is an asset to consumers seeking easier access to more information, sites that lack credible information may jeopardize health rather than enhance wellness and the sheer number of commercial health sites may make it more challenging for consumers to find government and non-profit produced information. As with the general population, a scarcity of culturally appropriate, LGBT-specific health communication information may result in LGBT 
individuals receiving guidance from health information sources that may be misleading, inaccurate, or inappropriate. In addition, consumer concerns regarding privacy and confidentiality of personal health information that may be tracked, stored or made available online ${ }^{70}$ may be of particular concern to LGBT health consumers. These concerns, shared by many consumers, are exacerbated by the current legal and social environment in some states that that fail to provide protection from job discrimination and that prohibit certain sexual behaviors.

The Internet and the World Wide Web have opened vast new channels for the distribution of traditional entertainment products and for a vast array of new ones, developed specifically by and for cyberspace visitors. Although the public health community has voiced some concerns about Internet chat rooms and websites that promote substance abuse and other risky behaviors among youth generally, much less attention has been paid to such activities designed to appeal specifically to LGBT individuals. The HIV/AIDS prevention community has reported numerous cyber vehicles promoting unsafe sexual practices, including many that include favorable references to the use of certain legal and illicit sexual-performance enhancing drugs (e.g., Viagra, Ecstasy, and methamphetamine.) However, no attempt has been made to quantify or analyze LGBT-targeted Internet and web entertainment and its relationship to substance abuse norms and practices within LGBT culture.

\section{PROVIDER/CONSUMER COMMUNICATION}

Effectiveness of communications on the micro level between health providers and consumers is also critical to quality care and improved health status. ${ }^{2,79}$ For example, a review of 96 studies found that risk communication interventions, particularly those that individualize assessment of risk in discussions between providers and patients, have positive effects on health outcomes. ${ }^{80}$ Consequently, Healthy People 2010 identifies an "increase in the proportion of persons who report that their health care providers have satisfactory communication skills" as a Health Communication Objective. ${ }^{62}$ Studies suggest that patients often find communication with physicians and other health professionals to be difficult. ${ }^{81}$ Physician failure to communicate and provide information to patients is associated with lower patient satisfaction and poorer health outcomes. ${ }^{79,82-84}$ Among women who have sex with women, problems with communication may contribute to delays in seeking care. ${ }^{85}$ Problems with communication have the potential to negatively impact transgender health outcomes such as liver complications caused by introducing new medications in conjunction with female hormones.

Provider capacity to listen to and treat patients with respect is increasingly a challenge given the growing diversity of health consumers, increasing complexity of many health interventions, and continuing pressures to limit time with patients. ${ }^{86}$ Specific structural issues may impede communication; for example, most health plans exclude treatment of any kind related to gender identity, including mental health services, and place transgender individuals in the position of withholding birth gender information. Despite these challenges, the capacity to communicate well with patients of different cultures and backgrounds may benefit providers as well as patients. For example, a study of training in effective intercultural communication found that improved capacity and confidence in communicating across cultures benefited health care providers by reducing their stress and anxiety. ${ }^{87}$ 
Communications between providers and LGBT health consumers may be substantially impaired by provider bias. Homophobia and discomfort in providing services to lesbian, gay, and bisexual consumers is common among health care providers. ${ }^{88-90}$ For example, a recent study of a sample of medical students found that approximately 25 percent believed homosexuality to be immoral and expressed aversion to interacting with homosexuals, 9 percent believed homosexuality to be a mental disorder and 14 percent reported feeling more homophobic since the advent of AIDS. ${ }^{91}$ In spite of these issues, content on homosexuality and bisexuality in medical curricula is largely absent or inadequate. $^{92}$ In addition, physicians often need to overcome additional layers of bias and unfounded assumptions when working with LGBT Latino, African American, Native American or Asian patients. ${ }^{93}$ The impact of the bias among health care professionals is voiced by the author of a qualitative study of lesbians of color in health care interactions who concludes that, "In the midst of any single encounter with a health care provider, they might have to decipher heterosexist remarks, steel themselves against racist epithets, counter undermining remarks insinuating gender inferiority, and heal from blows to their self esteem as they are badgered about their deservedness as uninsured clients. ${ }^{94,}$

Gaps in knowledge of and sensitivity to transgender issues among health providers have also been documented. Transgender individuals frequently encouter provider discomfort while attempting to seek out medical and or mental health services. The transition process, similar to the "coming-out" process, can be a very difficult time for transgender individuals attempting to increase self comfort levels. Health providers generally have insufficient training on the diversity of terms and dimensions of gender (e.g., biological sex, legal-institutional sex, social gender, and psychological gender) that are encompassed by the term "transgender." "95 "To non-transgendered people, the myriad terms and labels that many trans people use to identify themselves can appear to be ill-defined, confusing and sometimes contradictory." ${ }^{\text {„6 }}$ In addition, lack of knowledge about transgender identity and sexuality frequently results in health care professionals being educated by, and at the expense of, their patients. ${ }^{33}$ This role may be particularly overwhelming for transgender persons who may experience discrimination from health care professionals based on their gender-variant physical and social presentations. ${ }^{96}$ Concerns about potential insensitivity of service providers can be a barrier to accessing prevention and health services among transgender health consumers. ${ }^{34}$ Even when they are accessible, preventive health and health care services may not be appropriate. For example, individual HIV risk reduction and education interventions may be rendered ineffective when they are not transgender specific. ${ }^{34}$

Mental health providers and social workers in health also often face difficulties in communicating with LGBT patients because of homophobia and heterosexism ${ }^{97,98}$, failure to recognize how concerns of LGB clients differ from heterosexuals ${ }^{99,100}$, and inexperience with gender identity issues. ${ }^{101}$ For example, a random sample survey of mental health providers in one state found that respondents reported having lesbian clients, yet had little or no training about the special needs of these clients. ${ }^{100}$ Homophobic practices in the form of "conversion" or "reparative" therapies continue, although these practices are ineffective, unethical and affirm the need for practice that is evidence-based and consistent with professional principles. ${ }^{102,103}$ Many helping professionals untrained in working with sexual identity issues still routinely pathologize gender variance. For example, in a study examing the experiences of transgender individuals in psychotherapy it was reported that some therapists harm their patients by "belittling, challenging, 
or judgemental behaviors regarding the patient's gender.”101 In addition, current Standards of Care for Gender Disorders place the mental health professional in the role of gatekeeper in relation to accessing hormonal treatment or sexual reassignment medical services, a role that may undermine the therapeutic process. ${ }^{101}$

Many lesbian, gay and bisexual health consumers do not disclose their sexual orientation to health care providers. ${ }^{25,99,104,105}$ Reasons for non-disclosure may include fear of negative reactions or substandard care ${ }^{106}$ or belief that sexual orientation is not related to health care needs. ${ }^{107}$ Providers often fail to ask questions related to sexual behavior; most disclosures appear to be initiated by patients. ${ }^{85,107}$ A study of gay men found that general care providers and patients failed to discuss HIV risks (including safer sex or use of steroids). ${ }^{108}$ The authors suggest that identifying and addressing barriers to communication including provider discomfort, lack of knowledge, and concern about prolonging consultation time would increase opportunities for intervention. Although more research is needed on the effects of communication related to sexual orientation and medical care, emerging research suggests that successful communication and ease of sexual orientation disclosure may positively affect health behaviors and utilization of screening services. $^{24,85}$

Despite the issues outlined above, many LGBT health consumers are satisfied with their health care providers and place a high value on patient-provider relationships characterized by open communication. ${ }^{85,107}$ Opportunities for improved communication include greater initiative on the part of health providers in asking about sexual orientation, attending to concerns about past or potential discrimination in health services, and addressing avoidance of health services. ${ }^{106}$ There is also a documented need for pediatricians and other health providers to better address the health needs, gender specific issues, and confidentiality concerns of adolescent LGBT or questioning youth. $^{22,104,109}$ For example, a study of access and quality of care among LGBT youth found that 66 percent of youth stated that their health provider had never brought up issues of sexual orientation and that many received inappropriate treatment and health education based on their provider's inaccurate assumptions about the patient's sexual orientation. ${ }^{110}$ Adolescent gay, lesbian and bisexual youth appear to be more likely to disclose their sexual orientation when health providers discuss patient rights to confidentiality, however, providers do not uniformly provide these assurances ${ }^{104}$.

\section{SUMMARY AND RECOMMENDATIONS}

The field of health communications has been influenced by a number of changes in recent years. Greater recognition that individual health behaviors occur in and are influenced in a dynamic interaction with the larger political, economic and social environments has broadened the scope of health communications beyond a narrow focus on the individual as the target for change. ${ }^{44}$

New communication technologies offer opportunities for the exchange of health information and support. ${ }^{4,73,111}$ These technologies may be particularly salient for populations that may be isolated geographically (e.g., rural residents) or socially (e.g., lesbian, gay, bisexual, and transgender youth). Emerging research highlights promising strategies for changing health behaviors and environments through health communication. ${ }^{1,4}$ These research findings underscore the importance of multi-level health communication strategies (such as mass media messages combined with other community interventions), segmentation or targeting of specific 
audiences by demographics and other characteristics (e.g., values and beliefs), emphasis on the benefits of the proposed change, and addressing environmental factors related to the campaign. ${ }^{1 \text {, }}$ 6,112

For LGBT individuals, the cultural relevance of health communication activities, whether they are implemented in provider offices, community-based programs, the mass media, or another venue, plays an important role in determining whether health promotion and disease prevention messages are heard, understood, accepted, and practiced. Specific recommendations for advancing LGBT health communications are discussed in four specific areas: services, education and training, policy, and research.

\section{Services}

- Clinical care providers for LGBT individuals need to create a safe and culturally responsive environment and adopt standards for examining risk patterns, communicating options for risk reduction, and supporting the adoption of healthy behavior.

- Targeted health information should be delivered to high-risk and hard-to-reach LGBT individuals directly in their social contexts, including neighborhoods, social environments, and workplaces.

- LGBT individuals identified as at risk require access to evidence-based individual and small group interventions. These interventions should be non-stigmatizing, focused on reducing harm associated with risk behaviors, and based on client strengths and motivation for change.

- Community-level interventions targeted to diverse LGBT communities could be further developed to influence health-supporting practices and policies.

- LGBT specific health communications that are interactive, accessible to individuals of different literacy levels, and that facilitate shared decision making with providers need to be developed and evaluated.

\section{Education and Training}

- Health care providers of all disciplines should be provided with education and training on how to communicate with LGBT consumers and families in a culturally competent way and how to reduce barriers to effective communication.

- Education on sexual orientation, sexuality, and gender varience should be integrated into schools training health providers. Possible curricula elements to enhance student capacity to provide sensitive care include didactic instruction, discussion, simulated patient interactions, and supervised work with patients. ${ }^{113}$

- Health, mental health, and substance abuse treatment providers can improve their practice with all clients through training on how to take appropriate sexual histories without presuming heterosexuality ${ }^{114}$ and about communicating effectively in the context of gender variance.

Policy and Advocacy 
- Mainstream health communication specialists and health advocates can better reach LGBT populations by collaborating with LGBT media, LGBT health community organizations, and LGBT leaders.

- Government sponsored efforts to reduce health disparities and improve community health should continue and expand inclusion of goals and strategies specific to LGBT communities.

- Efforts to build healthy community norms can be supported through interventions aimed at LGBT organizations and communities (e.g., development of policies about responsible beverage services, alcohol and tobacco promotions, and promotion of counteradvertisement).

Research

- Research is needed to determine if access to LGBT-specific health information improves health-seeking behaviors, increases access to care, enhances knowledge, and yields better health outcomes for LGBT consumers and families.

- Multi-level health communication and promotion efforts targeting LGBT populations should be funded, monitored, and evaluated. Examination of the feasibility, appropriateness, and outcome of interventions previously tested with non-LGBT populations and subsets of the LGBT community not previously studied would be particularly useful.

- Research is needed to determine the most appropriate health communication strategies for hard-to-reach LGBT populations such as transgender subgroups, those in rural areas, Native Americans, and persons with disabilities.

- Centers for excellence on LGBT health should be supported, enhanced, and expanded. Information on best practices and successful models that come out of these LGBTfocused centers for excellent should be broadly disseminated to public- and private sector health professionals and health plans.

\section{REFERENCES}

1. Hornick, R.C. Public Health Communication: Evidence for Behavior Change. Lawrence Erlbaum Associates: Mahwah, New Jersey, 2002.

2. Jackson, L.D.; Duffy B.K.E. Health Communication Research. Greenwood: Westport, CT, 1998.

3. National Cancer Institute. Making Health Communications Work, Pub. No. NIH 891493; U.S. Department of Health and Human Services (DHHS): Washington, DC, 1989.

4. Rogers, E.M. The Field of Health Communication Today: An Up-To-Date Report. Journal of Health Communication 1996, 1, 15-23.

5. $\quad$ Piotrow, P.T.; Kincaid D.L.; Timon J.G.; Rinehart W. Health Communication: Lessons from Family Planning and Reproductive Health. Praeger: Westport, Connecticut, 1997.

6. Backer, T.E.; Rogers E.M.; Sopory P. Designing Health Communication Campaigns: What Works? Sage Publications: Newbury Park, CA, 1992. 
7. Atkin, C.; Wallack L. Mass Communication and Public Health. Sage Publications: Newbury Park, CA, 1990.

8. Holder, H. Public Health Approaches to the Reduction of Alcohol Problems. Substance Abuse 1994, 15(2), 123-138.

9. Mosher, J. A Public Health Approach to Alcohol and other Drug Problems: Theory and Practice. In Principles of Public Health Practice; Scutchfield, F.D., Keck C.W., Eds; Delmar Publisher: Albany, NY, 1996, p. 243-260.

10. Kegeles, S.M. The Mpowerment Project: A Community-Level HIV Prevention Intervention for Young Gay Men. American Journal of Public Health 1996, 86(8), 1129-1136.

11. Kelly, J.A.; St. Lawrence J.S.; Stevenson Y.; Hauth A.C.; Kalichman S.C.; Diaz Y.E.; Brasfield T.L.; Koob J.J.; Morgon M.G. Community AIDS/HIV Risk Reduction: The Effects of Endorsements by Popular People in Three Cities. American Journal of Public Health 1992, 82(11), 1483-1489.

12. Myrick, R. In the Life: Culture-Specific HIV Communication Programs Designed for African American Men who Have Sex with Men. Journal of Sex Research 1999, 36(2), 159-170.

13. Silvestre, A. Brokering: A Process for Establishing Long-Term and Stable Links with Gay Male Communities for Research and Public Health Education. AIDS Education and Prevention 1994, 6(1), 65-73.

14. CDCAIDSCommunityDevelopmentProjectsResearchGroup. Community-Level HIV Intervention in 5 Cities: Final Outcome Data From the CDC AIDS Community Demonstration Projects. American Journal of Public Health 1999, 89(3), 336-345.

15. Dearing, J.W.; Rogers E.M.; Meyer G.; Casey M.K.; Rao N.; Campo S.; Henderson G.M. Social Marketing and Diffusion-Based Strategies for Communicating with Unique Populations: HIV Prevention in San Francisco. Journal of Health Communication 1996, 1, 343-363.

16. Pulley, L.V.; McAlister A.L.; Kay L.S.; Reilly K.O. Prevention Campaigns for Hard-toReach Populations at Risk for HIV Infection: Theory and Implementation. Health Education Quarterly 1996, 23(4), 488-496.

17. Sell, R.L.; Becker J.B. Sexual Orientation Data Collection and Progress Toward Healthy People 2010. American Journal of Public Health 2001, 91(6), 876-882.

18. Cochran, S.D.; Mays V.M. Relation Between Psychiatric Syndromes and Behaviorally Defined Sexual Orientation in a Sample of the US Population. American Journal of Epidemiology 2000, 151(5), 516-523.

19. Skinner, W.F. The Prevalence and Demographic Predictors of Illicit and Licit Drug use Among Lesbians and Gay Men. American Journal of Public Health 1994, 84(8), 1307-1310.

20. Stall, R. Prevalence of Tobacco Smoking Among Gay/Bisexual men. In: APHA 125th Annual Meeting and Exposition; 1996 November; Indianapolis, IN: American Public Health Association; 1996. p. 110.

21. Diamant, A.L.; Schuster M.A.; McGuigan K.; Lever J. Lesbians' Sexual History with Men: Implications for Taking a Sexual History. Archives of Internal Medicine 1999, 159(22), 2730-2736. 
22. Saewyc, E.M.; Bearinger L.H.; Heinz P.A.; Blum R.W.; Resnick M.D. Gender Differences in Health and Risk Behaviors Among Bisexual and Homosexual Adolescents. Journal of Adolescent Health 1998, 23(3), 181-188.

23. Bradford, J.; Ryan C.; Rothblum E.D. National Lesbian Health Care survey: Implications for Mental Health Care. Journal of Consulting and Clinical Psychology 1994, 62(2), 228-242.

24. Rankow, E.J.; Tessaro I. Cervical Cancer Risk and Papnicolaou Screening in a Sample of Lesbian and Bisexual Women. Journal of Family Practice 1998, 47(2), 139-143.

25. White, J.C.; Dull V.T. Health Risk Factors and Health-Seeking Behavior in Lesbians. Journal of Women's Health 1997, 6(1), 103-112.

26. Blake, S.M.; Ledsky R.; Lehman T.; Goodenow C.; Sawyer R.; Hack T. Preventing Sexual Risk Behaviors Among Gay, Lesbian, and Bisexual Adolescents: The Benefits of GaySensitive HIV Instruction in Schools. American Journal of Public Health 2001, 91(6), 940-946.

27. Garofalo, R.; Wolf C.; Kessel S.; Palfrey J.; DuRant R.H. The Association Between High Risk Behaviors and Sexual Orientation Among a School-based Sample of Adolescents. Pediatrics 1998, 101(5), 895-902.

28. Noell, J.W.; Ochs L.M. Relationship of Sexual Orientation to Substance Abuse, Suicidal Ideation, Suicide Attempts, and Other Factors in a Population of Homeless Adolescents. Journal of Adolescent Health 2001, 29(1), 31-36.

29. Rotheram-Borus, M.J.; Rosario M.; Van Rossem R.; Reid H.; Gillis R. Prevalence, Course, and Predictors of Multiple Problem Behaviors Among Gay and Bisexual Male Adolescents. Developmental Psychology 1995, 31(1), 75-85.

30. Savin-Williams, R.C. Verbal and Physical Abuse as Stressors in the Lives of Lesbian, Gay Male, and Bisexual Youths: Associations with School Problems, Running Away, Substance Abuse Prostitution, and Suicide. Journal of Consulting and Clinical Psychology 1994, 62(2), 261-269.

31. Shifrin, F.; Solis M. Chemical Dependency in Gay and Lesbian Youth. Journal of Chemical Dependency Treatment 1992, 5(1), 67-76.

32. Greene, J.M.; Ennett S.T.; Ringwalt C.L. Substance Use Among Runaway and Homeless Youth in Three National Samples. American Journal of Public Health 1997, 87(2), 229-235.

33. Bockting, W.O.; Robinson B.E.; Rosser B.R.S. Transgender HIV Prevention: A Qualitative Needs Assessment. AIDS Care 1998, 10(4), 505-526.

34. Clements, K.; Wilkinson W.; Kitano K.; Marx R. HIV Prevention and Health Service Needs of the Transgender Community in San Francisco. International Journal of Transgenderism 1999, 3(1-2), http://www.symposion.com/ijt/hiv_risk/clements.htm.

35. Kenegy, G.P. HIV Among Transgendered people. AIDS Care 2002, 14(1), 127-144.

36. Xavier, J.M. The Washington, DC Trangender Needs Assessment Survey; Gender Education and Advocacy: Washington DC, 2000 August 24.

37. Yep, G.A.; Pietri M. In Their Own Words: Communication and the Politics of HIV Education for Transgenders and Transsexuals in Los Angeles. In Power in the blood: A 
Handbook on AIDS, Politics, and Communication.; Elwood, W.N., Ed.; Lawrence Earlbaum: Mahwah, NJ, 1999, p. 199-213.

38. DeJong, W.; Wolf C.; Austin S.B. U.S. Federally Funded Television Public Service Announcements (PSAs) to Prevent HIV/AIDS: A Content Analysis. Journal of Health Communication 2001, 6, 249-263.

39. Hornick, R.C. Public Health Communication: Making Sense of Contradictory Evidence. In Public Health Communication: Evidence for Behavior Change; Hornick, R.C., Ed.; Lawrence Erlbaum Associates: Mahwah, New Jersey, 2002, p. 1-19.

40. Simons-Morton, B.G.; Donohew L.; Crump A.D. Health Communication in the Prevention of Alcohol, Tobacco, and Drug Use. Health Education \& Behavior 1997, 24(5), 544554.

41. Kroger, F. Toward a Healthy Public: Models, Meanings and Messages. American Behavioral Scientist 1994, 38(2), 215-223.

42. Guttman, N.; Ressler W.H. On Being Responsible: Ethical Issues in Appeals to Personal Responsibility in Health Campaigns. Journal of Health Communication 2001, 6, 117-136.

43. Airhihenbuwa, C.O.; Obregon R. A Critical Assessment of Theories/Models Used in Health Communication for HIV/AIDS. Journal of Health Communication 2000, 5(Supplement), 5-15.

44. Green, L.W.; Kreuter M., W. Health Promotion Planning: An Educational and Ecological Approach. Third ed. Mayfield Publishing Company: Mountain View, CA, 1999.

45. Bockting, W.; Kirk E.; Sheila E. Transgender and HIV: Risks, Prevention, and Care. Haworth Press: New York, 2001.

46. Bockting, W.O.; Rosser B.R.S.; Scheltema K. Transgender HIV prevention: Implementation and evaluation of a workshop. Health Education Research 1999, 14(2), 177-183.

47. Melkote, S.R.; Muppidi S.R.; Goswami D. Social and Economic Factors in an Integrated Behavioral and Societal Approach to Communications in HIV/AIDS. Journal of Health Communication 2000, 5(Supplement), 17-27.

48. Ray, E.B. Communication and Disenfranchisement: Social Health Issues and Implications. Lawrence Erlbaum Associates: Mahway, New Jersey, 1996.

49. Mills, T.C.; Stall R.; Pollack L.; Paul J.P.; Binson D.; Canchola J.; Catania J.A. HealthRelated Characteristics of Men Who Have Sex with Men: A Comparison of Those Living in "Gay Ghettos" With Those Living Elsewhere. American Journal of Public Health 2001, 91(6), 980-983.

50. Kreuter, M.W.; Holt C.L. How do People Process Health Information? Applications in an Age of Individualized Communication. Current Directions in Psychological Science 2001, 10(6), 206-209.

51. Kreuter, M.W.; Oswald D.L.; Bull F.; Clark E.M. Are tailored health education materials always more effective than non-tailored messages? Health Education Research 2000, 15(3), 305315. 
52. Jernigan, D.H.; Wright P.A. Media Advocacy: Lessons from Community Experiences. Journal of Public Health Policy 1996, 17(3), 306-329.

53. Wallack, L.; Dorfman L. Media Advocacy: A Strategy for Advancing Policy and Promoting Health. Health Education Quarterly 1996, 23(3), 293-317.

54. Dorfman, L.; Wallack L. Advertising Health: The Case for Counter-Ads. Public Health Reports 1993, 108(6), 716-726.

55. Goldman, L.K.; Glantz S.A. Evaluation of Antismoking Advertising Campaigns. Journal of the American Medical Association 1998, 279(10), 772-777.

56. Drabble, L.; Soliz G. Final Report. In Alive with Pleasure: Prevention of Tobacco and Alcohol Problems in Lesbian, Gay, Bisexual and Transgender Communities; Milbrae, CA: Pacific Research and Training Alliance; October, 1996. p. 1-18.

57. Brown, J.D.; Walsh-Childers K. Effects of Media on Personal and Public Health. In Media Effects: Advances in Theory and Research; Bryant, J., Zillman D., Eds; Lawrence Erlbaum Associates: Hillsdale, NJ, 1994, p. 389-415.

58. Christenson, P.G.; Henrisken L.; Roberts D.F. Substance Use in Popular Prime Time Television; Office of National Drug Control Policy: Washington, DC, 2000 January.

59. Roberts, D.F.; Chrstenson P.G. "Here's Looking at You, Kid," - Alcohol, Drugs and Tobacco in Entertainment Media; The Henry J. Kaiser Family Foundation and The National Center on Addiction and Substance Abuse at Columbia University.: Menlo Park, CA, 2000 February.

60. Roberts, D.F.; Henriksen L.; Christenson P.G. Substance Use in Popular Movies \& Music; Office of National Drug Control Policy \& DHHS Substance Abuse and Mental Health Services Administration: Washington, DC, April 1999.

61. Peterson, J.L.; Carballo-Dieguez A. HIV Prevention Among African-American and Latino Men who Have Sex with Men. In Handbook of HIV Prevention; Peterson, J.L., DiClemente R.J., Eds; Plenum: New York, 2000, p. 217-224.

62. U.S. Department of Health and Human Services. Healthy People 2010, 2nd ed.; U.S. Government Printing Office: Washington DC, 2000.

63. Seldon, C.R.; Zorn M.; Ratzan S.; Parker R.M. Health Literacy; Current Bibliographies in Medicine, No. 2001-1, http://www.nlm.nih.gov/pubs/cbm/hliteracy.html; National Library of Medicine, February 2000.

64. Brown, J.A. Media Literacy Perspectives. Journal of Communication 1998, 48(1), 44-57.

65. Lewis, J.; Jhally S. The Struggle Over Media Literacy. Journal of Communication 1998, 48(1), 109-121.

66. Drabble, L. Alcohol, Tobacco, and Pharaceutical Industry Funding: Considerations for Organizations Serving Lesbian, Gay, Bisexual and Transgender Communities. Journal of Gay \& Lesbian Social Services 2000, 11(1), 1-26.

67. Penaloza, L. We're Here, We're Queer, and We're Going Shopping! A Critical Perspective on the Accommodation of Gays and Lesbians in the U.S. Marketplace. Journal of Homosexuality 1996, 31(1/2), 9-41. 
68. Rahn, P. Alcohol Marketing to the Gay Community. Prevention Pipeline 1994, 7(6), 3031.

69. Mosher, J.; Frank E. Reaching Consensus: Assessing Support for National Alcohol Policies. Presentation at the 122nd Annual Meeting of the American Public Health Association, Washington DC, November 1994.

70. Science Panel on Inteactive Communication and Health. Wired for Health and WellBeing: The Emergence of Interactive Health Communication; US Department of Health and Human Services, U.S. Government Printing Office: Washington, DC, April 1999.

71. Street, R.L.; Gold W.R.; Manning T., Eds. Heath Promotion and Interactive Technology: Theoretical Applications and Future Directions. Lawrence Erlbaum Associates: Mahwah, New Jersey, 1997.

72. Chamberlain, M.A. Health Communication: Making the Most of New Media Technologies-An International Overview. Journal of Health Communication 1996, 1, 43-50.

73. CommitteeonEvaluatingClinicalApplicationsofTelemedicine. Telemedicine: A Guide to Assessing Telecommunications for Health Care. Institute of Medicine, National Academy Press: Washington, DC, 1996.

74. Wennberg, J. Shared Decision Making and Multimedia. In Health and the New Media: Technologies Transforming Personal and Public Health; Harris, L.M., ed., Ed.; Lawrence Earlbaum Associates: Mahwah, New Jersey, 1995, p. 109-126.

75. Preston, J. Rural Health and the New Media. In Health and the New Media: Technologies Transforming Personal and Public Health; Harris, L.M., Ed.; Lawrence Earlbaum Associates: Mahwah, New Jersey, 1995, p. 65-86.

76. Gorry, G.A.; Harris L.M.; Silva J.; Eaglin J. Health Care as Teamwork: The Internet Collaboratory. In Health and the New Media: Technologies Transforming Personal and Public Health; Harris, L.M., Ed.; Lawrence Earlbaum Associates: Mahwah, New Jersey, 1995, p. 87105.

77. Office of Disease Prevention and Health Promotion. Health Communication. In U.S. Department of Health and Human Services, Healthy People 2010. Understanding and Improving Health and Objectives for Improving Health.

http://www.health.gov/healtypeople/document/HTML/Volume1/11HealthCom.htm, 2000

78. Shernoff, M. Cyber Counseling for Queer Clients and Clinicians. Journal of Gay \& Lesbian Social Services 2000, 11(4), 105-111.

79. Roter, D. Which Facets of Communication Have Strong Effects on Health Outcome--A Meta-Analysis. In Communicating with Medical Patients; Stewart, M., Roter D., Eds; Sage: Newbury Park, CA, 1989, p. 183-196.

80. $\quad$ Edwards, A.; Hood K.; Matthews E.; Russell D.; Russell I.; Barker J.; Bloor M.; Burnard P.; Covey J.; Pill R.; Wilkinson C.; Stott N. The Effectiveness of One-to-one Riskcommunication Interventions in Health Care. Medical Decision Making 2000, 20, 290-297.

81. Roter, D.L.; Hall J.A. Doctors Talking with Patients/Patients Talking with Doctors: Improving Communication in Medical Visits. Auburn House: Westport, CT, 1992. 
82. Cline, R.J.; McKenzie N.J. The Many Cultures of Health Care: Difference, Dominance, and Distance in Physician-Patient Communication. In Health Communication Research; Jackson, L.D., Duffy B.K.E., Eds; Greenwood: Westport, CT, 1988, p. 57-74.

83. DiMatteo, M.R.; Lepper H. Promoting Adherence to Courses of Treatment: Mutual Collaboration in the Physician-Patient Relationship. In Health Communication Research; Jackson, L.D., Duffy B.K.E., Eds; Greenwood: Westport, CT, 1998, p. 75-86.

84. Kaplan, S., D; Greenfield S.; Ware J.E. Impact of the Doctor-Patient Relationship on the Outcomes of Chronic Disease. In Communicating with Medical Patients; Stewart, M., Roter D., Eds; Sage: Newbury Park, CA, 1989, p. 228-245.

85. White, J.C.; Dull V.T. Room for Improvement: Communication between Lesbians and Primary Care Providers. Journal of Lesbian Studies 1998, 2(1), 95-110.

86. Osborn, J.E. Communication and the Health of the Public. Patient Education \& Counseling 2000, 41(2), 127-136.

87. Ulrey, K.L.; Amason P. Intercultural Communication Effectiveness, Cultural Sensitivity, Stress, and Anxiety. Health Communication 2001, 13(4), 449-463.

88. Schwanberg, S.L. Health Care Professionals' Attitudes Toward Lesbian Women and Gay Men. Journal of Homosexuality 1996, 31(3), 71-83.

89. Matthews, W.C.; Booth M.W.; Turner J.D.; Kessler L. Physicians' Attitudes Toward Homosexuality: Survey of a California County Medical Society. Western Journal of Medicine 1986, 144, 106-111.

90. Walpin, L. Combating heterosexism: Implications for nursing. Clinical Nurse Specialist 1997, 11(3), 126-132.

91. Klamen, D.L.; Kopacz D.R. Medical Student Homophobia. Journal of Homosexuality 1999, 37(1), 53-63.

92. Tesar, C.M.; Rovi S.L. Survey of Curriculum on Homosexuality/Bisexuality in Departments of Family Medicine. Family Medicine 1998, 30(4), 283-287.

93. Wainberg, M.L. The Hispanic, Gay, Lesbian, Bisexual and HIV-Infected Experience in Health Care. Mount Sinai Journal of Medicine 1999, 66(4), 263-266.

94. Stevens, P.E. The Experiences of Lesbians of Color in Health Care Encounters: Narrative Insights for Improving Access and Quality. Journal of Lesbian Studies 1998, 2(1), 77-94.

95. Lombardi, E. Enhancing Transgender Health Care. American Journal of Public Health 2001, 91(6), 869.

96. Lawrence, A.; Shaffer J.; Snow W.; Chase C.; Headlam B. Heatlh Care Needs of Transgender Patients. Journal of the American Medical Association 1996, 276, 874.

97. Berkman, C.S.; Zinberg G. Homophobia and Heterosexism in Social Workers. Social Work 1997, 42(4), 319-332.

98. Faria, G. The Challenge of Health Care Social Work with Gay Men and Lesbians. Social Work in Health Care 1997, 25(1/2), 65-72. 
99. Robertson, A.E.; Patterson D.L. The Mental Health Experiences of Gay Men: A Research Study Exploring Gay Men's Health Needs. Psychiatric Mental Health Nurses 1998, 5(1), 33-40.

100. Ryan, C.; Bradford J.B.; Honnold J.A. Social Workers' and Counselors' Understanding of Lesbian Needs. Journal of Gay \& Lesbian Social Services 1999, 9(4), 1-26.

101. Rachlin, K. Transgender Individuals' Experience of Psychotherapy. International Journal of Transgenderism 2002, 6(1), http://www.symposion.com/ijt/ijtvo06no1_03.htm.

102. Alexander, C.J. Reparative Therapy for Gays and Lesbians. Journal of Gay and Lesbian Social Services 1999, 9(4), 115-118.

103. Haldeman, D.C. The Practice and Ethics of Sexual Orientation Conversion Therapy. Journal of Consulting and Clinical Psychology 1994, 62(2), 221-227.

104. Allen, L.B.; Glicken A.D.; Beach R.K.; Naylor K.E. Adolescent Health Care Experience of Gay, Lesbian, and Bisexual Young Adults. Journal of Adolescent Health 1998, 23(4), 212-220.

105. Cochran, S.D.; Mays V.M. Disclosure of Sexual Preference to Physicians by Black Lesbian and Bisexual Women. Western Journal of Medicine 1988, 149, 616-619.

106. Stein, G.L.; Bonuck K.A. Physician-Patient Relationships among the Lesbian and Gay Community. Journal of the Gay \& Lesbian Medical Association 2001, 5(3), 87-93.

107. Beehler, G.P. Confronting the Culture of Medicine: Gay Men's Experience with Primary Care Physicians. Journal of the Gay \& Lesbian Medical Association 2001, 5(4), 135-141.

108. Elford, J.; Bolding G.; Maguire M.; Sherr L. Do Men Discuss HIV Risk Reduction with their GP? AIDS Care 2000, 12(3), 287-290.

109. East, J.A.; El Rayess F. Pediatricians' Approach to the Health Care of Lesbian, Gay and Bisexual Youth. Journal of Adolescent Health 1998, 23(4), 191-193.

110. Kreiss, J.L.; Patterson D.L. Psychosocial Issues in Primary Care of Lesbian, Gay, Bisexual and Transgender Youth. Journal of Pediatric Health Care 1997, 1, 266-274.

111. Harris, L.M., Ed. Health and the New Media: Technologies Transforming Personal and Public Health. Lawrence Erlbaum Associates: Mahwah, NJ, 1995.

112. Maiback, E.; Parrot R.L. Designing Health Messages: Approaches from Communication Theory and Public Health Practice. Sage Publications: Thousand Oaks, CA, 1995.

113. Robinson, G.; Cohen M. Gay, Lesbian and Bisexual Health Care Issues and Medical Curricula. Cmaj 1996, 155(6), 709-711.

114. Roberts, S.J.; Sorenson L. Lesbian Health Care. Nurse Practitioner 1995, 20(6), 42-47. 